\title{
Drylines in Argentina: Synoptic Climatology and Processes Leading to Their Genesis
}

\author{
HERnÁn Bechis, PAOla SAlio, AND JuAn José Ruiz \\ Centro de Investigaciones del Mar y la Atmósfera/CONICET-UBA, Departamento de Ciencias de la Atmósfera y los \\ Océanos, FCEyN, UBA, UMI-IFAECI 3355 CNRS-CONICET-UBA, Buenos Aires, Argentina
}

(Manuscript received 25 February 2019, in final form 3 October 2019)

\begin{abstract}
Drylines have been identified as relevant synoptic-scale phenomena that frequently occur in several regions around the world. Despite previous works and the experience of local forecasters that recognizes the occurrence of drylines in Argentina and suggests its possible association with convection initiation, knowledge about the mechanisms leading to the genesis of these features is poor. This paper presents the first synoptic climatology of these drylines as well as a first approach to the understanding of the processes leading to their formation. The climatology is based on an automated algorithm for dryline identification applied to reanalysis data. We found that drylines are more frequent between the northern Patagonia plateau and the central Argentinean plains. A composite analysis is performed to analyze the processes leading to the formation of synoptic-scale drylines within this region. It was found that these drylines form in the confluence between a warm and moist air mass driven by a northwesterly flow and drier air flowing east over the northern Patagonia plateau. The dry air originates on top of the Pacific maritime boundary layer and experiences lee subsidence after crossing the Andes range creating an area of dry and warm air that is advected to the east by the westerly synoptic-scale flow, and transported downward during the day due to strong boundary layer turbulence. At the same time, surface heating over the plateau leads to substantial warming of the originally colder dry air behind the dryline, thus reversing the horizontal temperature gradient across the dryline.
\end{abstract}

\section{Introduction}

In a broad sense, the literature defines drylines as airmass boundaries characterized by a sharp horizontal contrast in the low-level humidity fields (Owen 1966; Schaefer 1974). Those that form over the Great Plains of the United States are the most widely studied and are considered as a preferential zone for convection initiation (Wilson and Roberts 2006) which can lead, under favorable conditions, to severe weather events (Lin 2007). Drylines are also found in other regions of the world (Schaefer 1986) like India (Weston 1972; Akter and Tsuboki 2017), eastern China (Golden 1980; Qin and Chen 2017), central West Africa (Hamilton et al. 1945), Australia (Arnup and Reeder 2007), and Canada (Taylor et al. 2011). In each of these regions, drylines have their own characteristics and development mechanisms, which are strongly linked to local orography and regional synoptic climatology.

Dryline climatologies (i.e., the study of their frequency, spatial distribution, relation to diurnal and

Corresponding author: Hernán Bechis, hernan.bechis@ cima.fcen.uba.ar seasonal cycles, and associated synoptic conditions) have also been studied over different regions using different datasets and detection criteria. Usually, a conservative moisture variable is utilized to identify the dryline-either specific humidity or mixing ratioalthough some works use near-surface dewpoint temperature. In addition, conditions over the temperature field are often included to eliminate surface fronts, and on occasions, a wind shift across the dryline is required. Some studies (Owen 1966; Hoch and Markowski 2005; Schultz et al. 2007) use surface observations to manually detect drylines. Based on this approach they found that drylines are observed over the U.S. Great Plains on $32 \%-45 \%$ of the spring season days (April, May, and June). Duell and Van Den Broeke (2016) developed an objective algorithm to detect drylines in the Mississippi River valley (United States), where drylines are less frequent, using data from the North American Regional Reanalysis (NARR). A detection procedure suitable for high-resolution numerical models is presented by Clark et al. (2015). Their algorithm includes image processing and pattern recognition techniques applied to various meteorological fields, and machine learning algorithms to further refine the results. This last step helps to better 
distinguish drylines from other low-level boundaries such as cold fronts intersecting a dryline, weak cold fronts, among others.

In the literature, several mechanisms have been proposed to explain the strength of the low-level moisture gradient leading to the formation of drylines. Frontogenesis caused by shearing deformation and confluence acting over the moisture fields is one of them (Anthes et al. 1982; Ziegler et al. 1995). Drylines can also appear as a consequence of inhomogeneities in land cover type or soil conditions. For example, strong differences in soil moisture can lead to horizontal gradients in surface moisture fluxes which can directly affect the moisture content of the planetary boundary layer. Differences in land cover can, for instance, produce horizontal gradients in heat fluxes. This can impact the height of the planetary boundary layer indirectly affecting its moisture content by changing the entrainment rate at its top. Surface inhomogeneities can also contribute to enhancing the low-level moisture gradient through mesoscale frontogenesis associated with solenoidal circulations (Sun and Ogura 1979). Schultz et al. (2007) surmises that once drylines appear, their intensity can be modulated by synoptic-scale frontogenesis, in combination with mesoscale circulations and microscale mixing processes.

In particular, studies over the U.S. Great Plains have found that both large-scale and mesoscale processes are involved in the formation and development of these drylines (Lin 2007). At large scales, relatively strong moisture gradients are generated by differential moisture advection. Moist and warm air from the Gulf of Mexico is advected northward to the lee of the Rockies while dry, warm air from the Mexican plateau is advected eastward. This warm and dry air often overruns the relatively cooler and more humid air from the Gulf of Mexico creating an elevated mixed layer (EML) atop the moist air mass. This generates a capping inversion which prevents the release of latent instability over large areas while enhancing the intensity of convective outbreaks over narrowly focused regions (Carlson et al. 1983).

On the eastern slope of the Andes Mountains over central Argentina, local forecasters acknowledge that drylines are a regular feature of the warm season climatology. Between the elevated arid northern Patagonia plateau (NPP; Fig. 1) dominated by a steppe landscape, and the lower, moister central Argentina plains (CAP) characterized by a grassland landscape, strong moisture gradients usually develop in the absence of a well-defined low-level front. These boundaries, which are frequently oriented northwest (NW)-southeast (SE), are sometimes associated with thunderstorm development, as revealed

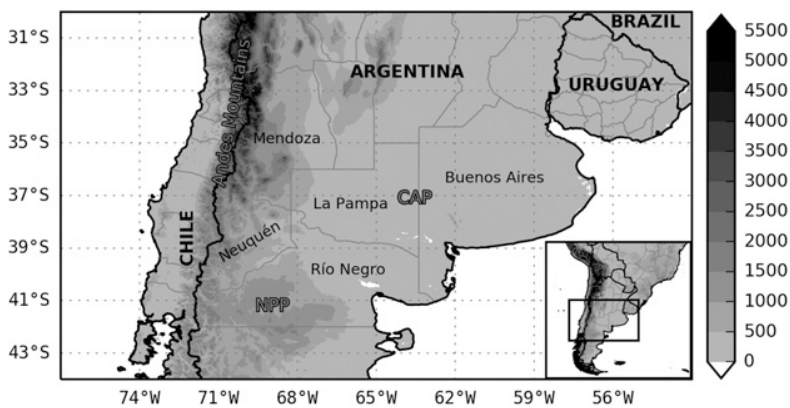

FIG. 1. Regional topography from the ETOPO 1 dataset (Amante and Eakins 2016) (m, shaded) and political boundaries. Northern Patagonian plateau (NPP) and central Argentinian plains (CAP). Gray lines indicate provincial limits. The names of the provinces named in the text are also included.

by satellite images, which may eventually lead to severe weather events.

Figure 2 shows an example of a dryline that developed on 20 December 2017 over central Argentina. Large dewpoint contrasts were observed at 1500 LT (1800 UTC) across this boundary that extends from southern Mendoza to eastern Río Negro (Fig. 2a). High temperatures associated with intense surface heating and clear sky conditions ahead of a cold front that advances over northern Patagonia contrast with similar or even slightly cooler temperatures north of the dryline (Fig. 2b). The satellite image shows deep convection developing ahead of the dryline, providing a proxy of its location in La Pampa province, where the surface network is quite coarse (Fig. 2c). The boundary can be identified as a zone of brightness temperature and cloudiness contrast in the GOES-16 10.3- $\mu \mathrm{m}$ satellite image. This image helps to estimate the location of the dryline, with some degree of uncertainty, particularly in areas where the density of surface weather stations is too coarse. Some of the storms that developed on that day became severe, as revealed by several hail and wind damage reports from social media and local newspapers. While surface observations near the central section of the dryline are scarce, in eastern Río Negro some of the automatic weather stations belonging to the Instituto Nacional de Tecnología Agropecuaria (National Institute of Agricultural Technology) captured the evolution of the dewpoint and temperature associated with the propagation of the dryline and, in combination with the National Weather Service surface network, allow for a more complete description of this event (Fig. 2d). Abrupt dewpoint drops can be seen starting early in the morningbetween 1000 and 1200 LT (1300 and 1500 UTC) - at San Antonio Oeste. Later on, General Conesa, and Río Colorado recorded similar dewpoint drops of about $10^{\circ} \mathrm{C}$ between 1500-1600 LT (1800-1900 UTC) and 

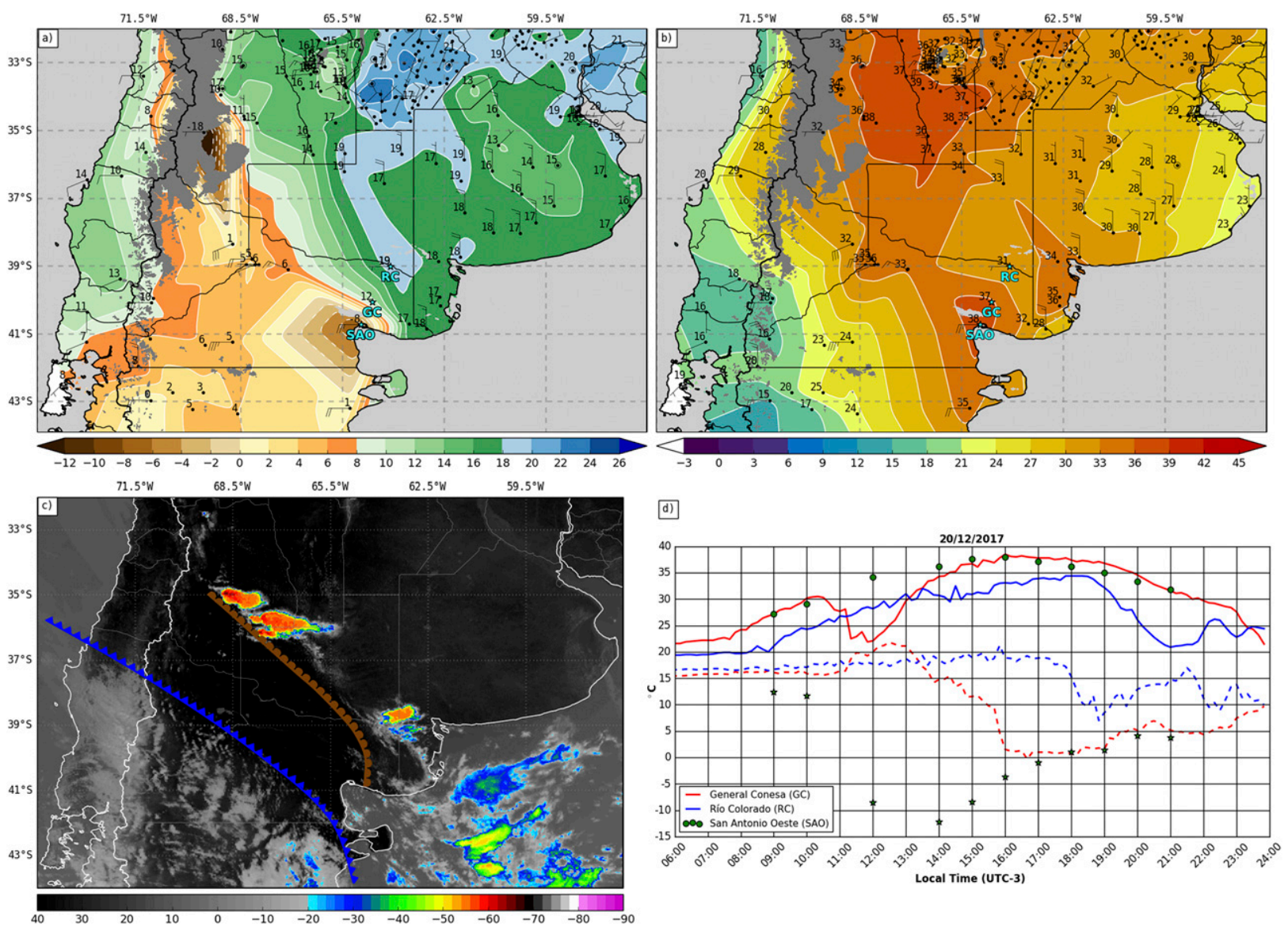

FIG. 2. Observations of (a) surface dewpoint and (b) temperature in south-central Argentina during the occurrence of a dryline at 1800 UTC 20 Dec 2017. (c) Corresponding GOES-16 ABI channel $13(10.3 \mu \mathrm{m})$ brightness temperature showing severe convective cells developing ahead of the dryline and a cold front advancing at 200-300 km behind it. (d) Time series of temperature and dewpoint at San Antonio Oeste, General Conesa, and Río Colorado, depicting the dryline passage at those stations.

1800-1900 LT (2100-2200 UTC), respectively, indicating a northeastern propagation of the dryline. The temperature at those stations does not show a significant change associated with the dryline passage, apart from some brief cooling at General Conesa at 1200 LT (1500 UTC) owing to some weak morning rains.

Other airmass boundaries that develop in the region have received considerable attention over the years, such as cold fronts with associated cold air incursions and their interaction with the Andes (Garreaud 2000; Seluchi et al. 2006) and warm fronts (Ribeiro et al. 2016), among others. However, despite the perceived importance of drylines for the regional weather and climate of central Argentina and their association with the development of severe weather, only a few studies have been carried out over the area. Lichtenstein and Schwarzkopf (1966) studied squall lines in Argentina and suggested that the development of a "dewpoint front" over central Argentina is favorable for squall line formation. They proposed that strong moisture gradients develop in this region under a low-level confluent (frontogenetical) flow, which contributes to increased contrast between a moist tropical air mass to the north of the line and dry, warm air, which moves leeward of the Andes slopes in a zone of prevailing westerly flow. The regional circulation that leads to this airmass contrast is linked to the characteristics of the topography. North of $35^{\circ} \mathrm{S}$ the Andes block the lowlevel flow, forcing a mainly meridional displacement of air masses. In particular, the channeling of warm, moist air masses from low latitudes leads to the formation of the South American low-level jet (Salio et al. 2002; Marengo et al. 2004). Farther south, the lower elevations of the Andes mountains and the stronger westerly winds, allow the South Pacific air masses to overpass the topography. In this process, a large part of the moisture content is turned into precipitation due to the orographically forced ascent over the western slopes of the Andes. Because of this process, the air mass that descends over the eastern Andes foothills is much drier and 
warmer. When this dry air over northern Patagonia meets moist air channeled southward by the northern Andes a large contrast in low-level moisture can result. As studied by Chou and Neelin (2001), this dry westerly flow helps to limit the southward propagation of warm and humid air masses thus limiting the meridional extent of continental deep moist convection during the warm season.

To the best of our knowledge, the characterization of the dryline climatology over central Argentina has never been attempted before. In the same way, the hypothesis regarding possible mechanisms of dryline formation in central Argentina as proposed by Lichtenstein and Schwarzkopf (1966) has not been analyzed in detail. Given these points and taking advantage of current data availability, the main goal of this paper is to present a characterization of drylines over central Argentina and to provide a first insight into the main synoptic mechanisms that lead to their formation. These goals are achieved by developing and implementing an automatic dryline detection algorithm. The detection algorithm is applied to 38 years of reanalysis data to evaluate the climatological characteristics of drylines in Argentina. Some selected events are utilized to create composites, to study the mechanisms that explain the strengthening of lowlevel moisture gradients and dryline formation over the region where drylines are most frequently detected.

This paper is outlined as follows: section 2 describes the data used and the formulation of the dryline detection algorithm, section 3 presents the results of its application and the analysis of the spatial distribution of the detected events as well as their frequencies. The annual and diurnal cycle of drylines is also explored in that section. Composites over some selected cases are also presented and analyzed in section 4 . In section 5 a summary and the conclusions drawn are presented.

\section{Data and methodology}

\section{a. Data}

This study uses the ERA-Interim reanalysis over the period 1979-2016 (Dee et al. 2011). Reanalysis data are chosen in the present work due to the lack of a dense surface observation network over the area of interest. ERA-Interim incorporates satellite data with a high spatial and temporal resolution, allowing a good representation of the atmospheric state, even over conventional data scarce areas. The reanalysis data are available at 6-h intervals in 27 pressure levels ranging from 1000 to $100 \mathrm{hPa}$, and in a horizontal grid spacing of $0.5^{\circ}$. Data for surface heat and moisture fluxes are taken from the 6-h forecasts verifying at the same time as the analysis. ERA-Interim assimilates surface observations of temperature, humidity and pressure over land making it particularly attractive for the representation of nearsurface processes like those associated with the development of drylines.

\section{b. Automated detection of drylines based on reanalysis data}

An automated dryline detection algorithm is developed and applied to the ERA-Interim data to identify dryline events over central Argentina. This algorithm is based upon the dryline detection criteria proposed by Duell and Van Den Broeke (2016) but includes some new considerations and modifications to adapt it to the study region. These modifications and extra considerations arise from the insight gained after a detailed observation of areas of strong moisture contrast over the study area during a period of 2 years, both using surface observations and reanalysis fields, to be sure that most of the objects detected by the objective algorithm correspond to features subjectively classified as drylines. The main goal of the algorithm is to identify synoptic-scale strong low-level moisture gradients which are not associated with a surface front. This procedure is also designed so that mesoscale boundaries associated with the land-sea breeze or coldpool circulations are not identified as drylines. The dryline detection algorithm employs an object-based approach that defines drylines starting from the detection of clusters of adjacent grid points that satisfy the following criteria:

\section{1) Moisture GRAdient}

The magnitude of the specific humidity gradient $(\nabla \mathbf{q})$ at $925 \mathrm{hPa}$ must be larger than $3 \mathrm{~g} \mathrm{~kg}^{-1}(100 \mathrm{~km})^{-1}$. This threshold is used by Duell and Van Den Broeke (2016) to generate a climatology of drylines in the Mississippi River valley using a reanalysis dataset with $32 \mathrm{~km}$ of horizontal grid spacing.

\section{2) Temperature gradient}

The magnitude of the potential temperature gradient $(\nabla \boldsymbol{\theta})$ at $925 \mathrm{hPa}$ must be lower than $0.2 \mathrm{~K}(100 \mathrm{~km})^{-1}$, or the angle between the $925 \mathrm{hPa} \nabla \mathbf{q}$ and $\nabla \boldsymbol{\theta}$ vectors must be greater than $90^{\circ}$ (measured either clockwise or counterclockwise). The same temperature gradient magnitude threshold was used by Duell and Van Den Broeke (2016). This condition is designed to remove frontal zones, where large temperature gradients are collocated with moisture gradients.

All the grid points located over the ocean or those for which the surface pressure is lower than $925 \mathrm{hPa}$ are not considered in the definition of the objects. Once the objects are defined based on criteria 1 and 2, additional criteria are applied to filter out those objects that do not correspond to dryline events: 


\section{3) OBJECT SIZE}

The objects are required to have a size of at least 10 grid points (roughly $20000 \mathrm{~km}^{2}$ ). The main purpose of this requirement is to retain only synoptic-scale features that are well represented with the current data resolution and to filter small-scale features like those associated with convection.

\section{4) THE STANDARD DEVIATION OF THE $925 \mathrm{HPA}$ $q$-GRADIENT VECTOR DIRECTION WITHIN THE OBJECT MUST NOT EXCEED $45^{\circ}$}

This condition removes features associated with strong convection, in which localized drying generates rings of large humidity gradients. In these types of objects, the direction of the $\nabla \mathbf{q}$ vector shows large variability, compared with synoptic-scale drylines.

5) THE OBJECT-WISE AVERAGED DIRECTION OF THE 925 HPA $q$-GRADIENT RELATIVE TO THE NORTH IS REQUIRED TO BE LARGER THAN $315^{\circ}$ OR LOWER THAN $135^{\circ}$

This is a reasonable assumption after preliminary analysis of the characteristics of drylines over the study area.

6) For A PARTICULAR OBJECT, THE NUMBER OF GRID POINTS MEETING CONDITIONS 1 AND 2 MUST BE LARGER THAN THE NUMBER OF GRID POINTS MEETING ONLY CONDITION 1

This is done to remove objects that meet all the previous conditions but are located on the edge of larger objects that are more consistent with surface fronts (e.g., surface fronts where the temperature and moisture contrasts are slightly out of phase).

Objects meeting all the above mentioned criteria are considered drylines while those which only meet criteria 1,3 , and 4 are labeled as $q$-gradient objects (i.e., regions of large humidity change, regardless of their thermal characteristics). Finally, the centroid location for a particular object is calculated as the average of the longitude and latitude of the grid points contained in it, and only the dryline objects whose centroids are within the limits of the domain shown in Fig. 1 are retained.

Figure 3 shows four examples of how the method can detect strong low-level moisture gradients and drylines. The first example corresponds to a dryline detected at 1800 UTC 8 February 2016 (Fig. 3a). In this case, there are two objects identified based on their strong humidity gradient at $925 \mathrm{hPa}$. Both objects meet the size criteria. The one located to the north is a ring-shaped object that possesses a dry and relatively warm center, that resulted from the activation of the cumulus parameterization in the model. This object meets all the criteria except the one which requires a small variability of the $\nabla \mathbf{q}$ vector direction within the object, so it is discarded. The southernmost object in Fig. 3a meets conditions 1, 3, and 4 , and for this reason, it is labeled as a $q$-gradient object. A subset of 29 consecutive grid points also meet conditions 2, 5, and 6 since the strong low-level moisture contrast occurs in an area where the temperature gradient is pointing to the south-southwest, thus this subset can be labeled as a dryline.

Another example of the identification process is shown in Fig. 3b (at 1800 UTC 15 January 2001). In this case a dryline similar to the one in Fig. 3 a is found on the edge of the NPP. In addition, a $q$-gradient object is detected on the Buenos Aires coast, associated with a land-sea moisture contrast. In the latter, most of the grid points show moisture and temperature gradients pointing onshore, so that this object cannot be classified as a dryline. Figure $3 c$ shows an example of a large object associated with an advancing cold front at 0600 UTC 12 January 2010, which is labeled as a $q$-gradient object. Several points of the southern edge of this object meet most of the conditions to be considered a dryline object. However, they do not meet condition number 6 since these are part of a much larger object that does not exhibit dryline characteristics. Finally, Fig. 3d corresponds to the same case shown in Fig. 2. The location of the lowlevel moisture gradient in the reanalysis data is properly located (in comparison with satellite and surface data) and the objective algorithm succeeds in identifying this area of low-level moisture contrast as a dryline.

\section{c. Composite analysis and mechanisms related to the dryline origin}

To analyze the processes that lead to dryline development over central Argentina, a composite analysis over some selected cases is performed. The selection process assures that the drylines in that sample show similar characteristics and will be described in section 4. To describe the synoptic patterns associated with dryline occurrence over central Argentina, averaged fields of specific humidity, temperature, wind, and geopotential height are computed, along with their standardized anomalies with respect to their corresponding monthly mean and standard deviation. To quantify the processes that may be involved in the formation of the drylines, we present an analysis of the terms of the water vapor conservation and thermodynamic equations. The water vapor conservation equation in pressure coordinates can be expressed as: 

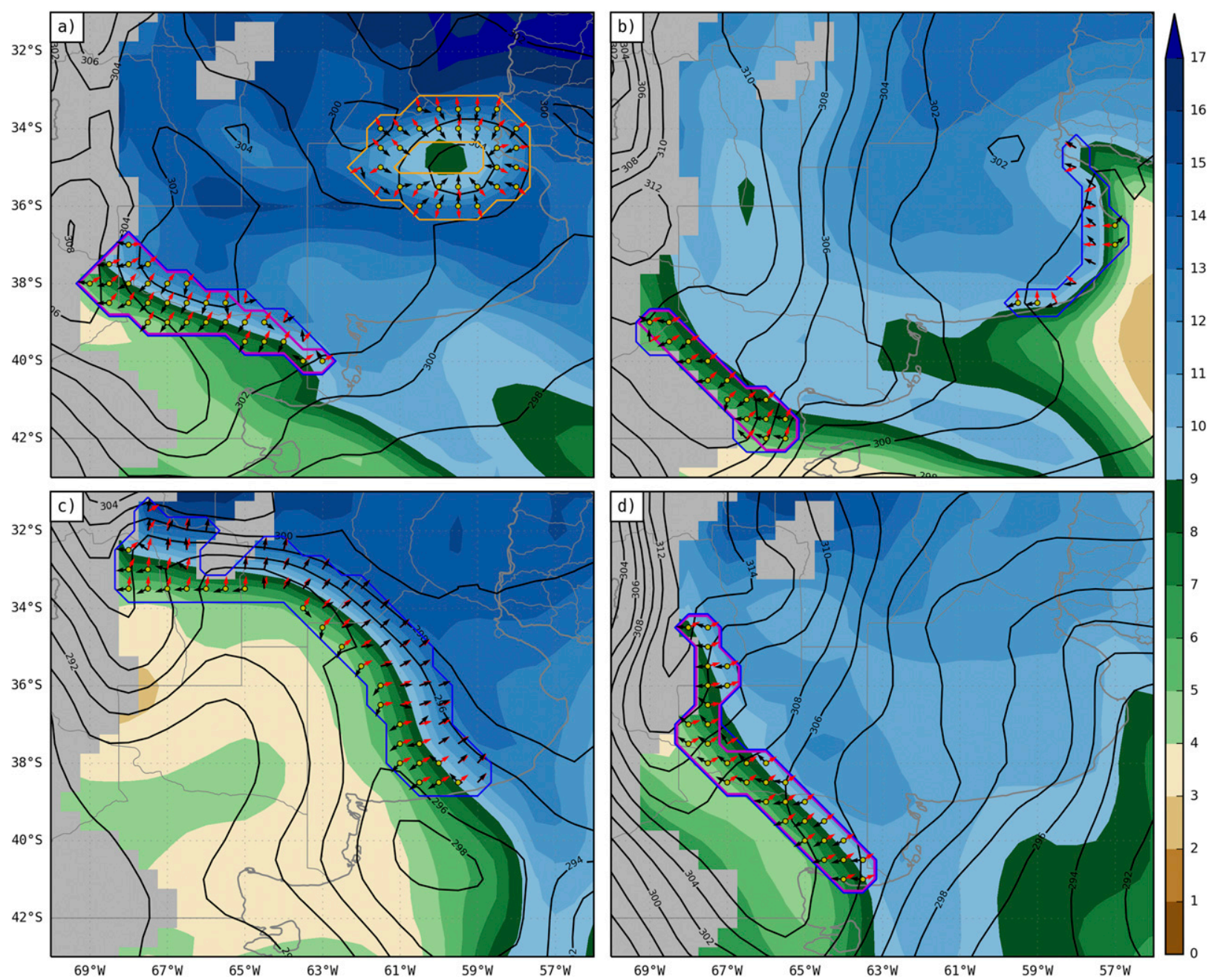

FIG. 3. Four different examples of the performance of the dryline detection algorithm. Specific humidity (shaded, $\mathrm{g} \mathrm{kg}^{-1}$ ) and potential temperature (contours, K) at the $925 \mathrm{hPa}$ level. Blue contour: $q$-gradient objects. Magenta contour: dryline object. Orange contour: object associated with deep moist convection. The orientation of the $\nabla \mathbf{q}$ and $\nabla \boldsymbol{\theta}$ vectors are indicated by the red and black arrows, respectively. Grid points within the objects where the angle between $\nabla \mathbf{q}$ and $\nabla \boldsymbol{\theta}$ is larger than $90^{\circ}$ are indicated by yellow dots.

$$
\frac{\partial q}{\partial t}=-\mathbf{V}_{h} \cdot \nabla_{p} \mathbf{q}-\omega \frac{\partial q}{\partial p}+S_{q}
$$

where $q$ is the specific humidity, $\mathbf{V}_{h}$ is the horizontal wind vector, and $\omega$ is the vertical velocity in pressure coordinates. The first two terms of the rhs of the equation correspond to the horizontal and vertical moisture advection. The third term in the rhs represents the sources and sinks of water vapor associated with phase changes in water substance, the divergence of turbulent fluxes and the vertical redistribution produced by deep moist convection. It is important to note that the first two terms of the rhs represent the component of the atmospheric transport that can be resolved by the model used to generate the reanalysis while the third term includes phase changes and unresolved transport whose effects are parameterized in the model.

The local temporal derivative on the lhs of the equation is calculated for each event using a backward first order finite difference. The horizontal and vertical advection terms are computed with centered first order finite differences in space and averaged over the two times used in the computation of the temporal derivative in order to make the comparison between these terms as fair as possible. The third term in the rhs is estimated as the difference between the local tendency and the resolved advection. It is worth noting that by approximating this term as a residual, the changes introduced in the moisture field by the assimilation of the observations will be spuriously considered as part of the moisture sources and sinks. 


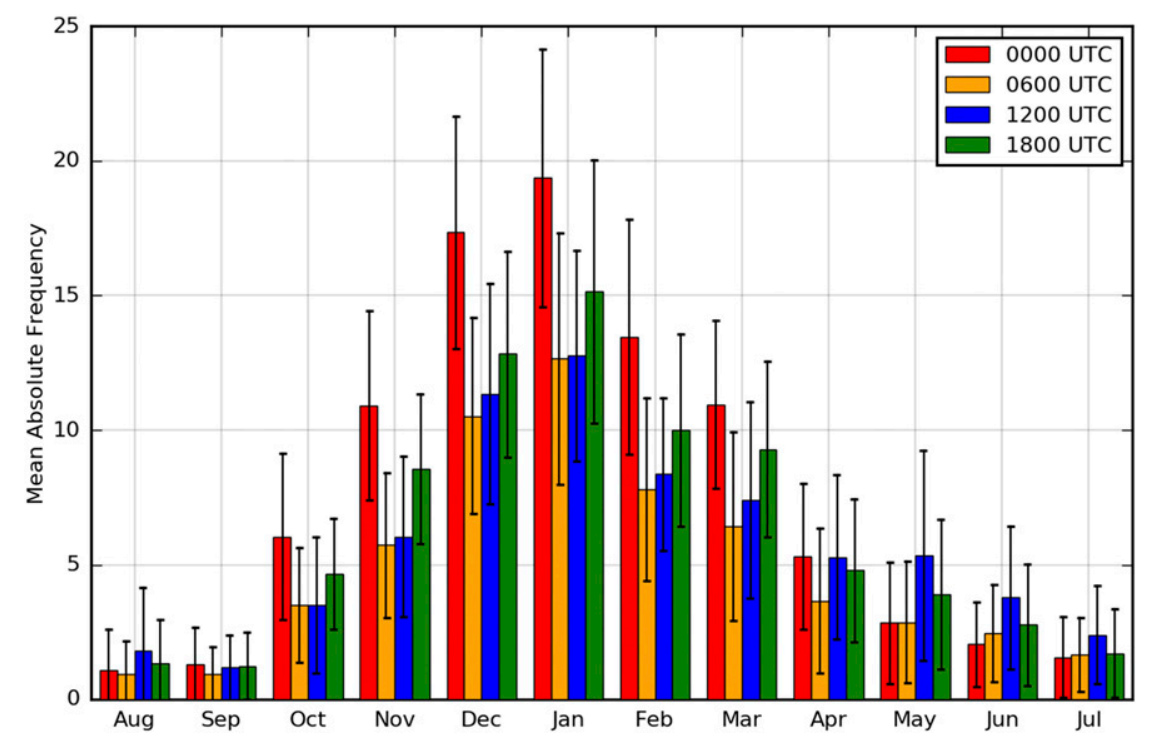

FIG. 4. Monthly mean absolute frequency of dryline objects detected in the 1979-2016 period at 0000 (red), 0600 (orange), 1200 (blue), and 1800 UTC (green). The error bars denote \pm 1 standard deviation.

The thermodynamic equation in pressure coordinates can be expressed as:

$$
\frac{\partial \theta}{\partial t}=-\mathbf{V}_{h} \cdot \nabla_{p} \boldsymbol{\theta}-\omega \frac{\partial \theta}{\partial p}+\left(\frac{\theta}{C_{p} T} \frac{d Q}{d t}\right),
$$

where $C_{p}$ is the specific heat of dry air at constant pressure. The lhs of the equation is the local variation of $\theta$ which depends on the resolved horizontal and vertical advection (first two terms on the rhs) and diabatic processes (third term rhs) which consider diabatic heating and the divergence of turbulent heat transport. The computation is done in a similar way as for the water vapor conservation equation where the lhs and the first two terms of the rhs are computed from the reanalysis data and the third term of the rhs is estimated as the difference between them. As noted before, the updates produced by the assimilation system upon the potential temperature will produce spurious contributions to the estimation of the third term in the rhs of the equation.

\section{Climatology of drylines in central Argentina}

This section discusses the climatology of the objects detected by the proposed algorithm, with particular emphasis on the annual and diurnal cycle of the drylines, as well as their spatial distribution.

\section{a. Annual cycle and geographical distribution of drylines}

The annual cycle of the monthly frequency of dryline objects over the entire domain computed over the entire period is shown in Fig. 4. The distribution of the monthly absolute frequencies shows maximum frequencies during the summer and late spring months, and lower values in autumn, winter, and early spring. The algorithm detects drylines more frequently in the evening and afternoon hours (0000 UTC and 1800 UTC) in the warm months, while in the colder months the frequencies are similar for the four synoptic times, with slightly higher frequencies at 1200 UTC. The standard deviation of dryline frequencies during the warm months is lower at 0000 UTC and 1800 UTC (with values representing $\sim 24 \%-35 \%$ of the mean), than at 0600 UTC and 1200 UTC ( $~ 30 \%-54 \%)$. January is the most favorable month for dryline occurrence, with a mean absolute frequency of 19 drylines per month at 0000 UTC. The summer peak in dryline occurrence is probably associated with the more frequent arrival to the region of tropical air masses from the north. This situation is favored by the southward displacement of the South Atlantic anticyclone and the recurrent development of the northwestern Argentinian low (Seluchi et al. 2003; Saulo et al. 2010), both enhancing the poleward transport of tropical moisture to the region. Based on Fig. 4, we define a warm season in which drylines are the most frequent as the 5-month period from November to March and a cold season as the 7-month period from April to October.

Figure 5 shows the number of times in a month in which each grid point is part of a dryline or a $q$-gradient object during the warm season, between 1979 and 2016, and at 0000, 0600, 1200, and 1800 UTC. Grid points where the surface pressure is below $925 \mathrm{hPa}$ more than $20 \%$ of the times are masked so the results represent a 

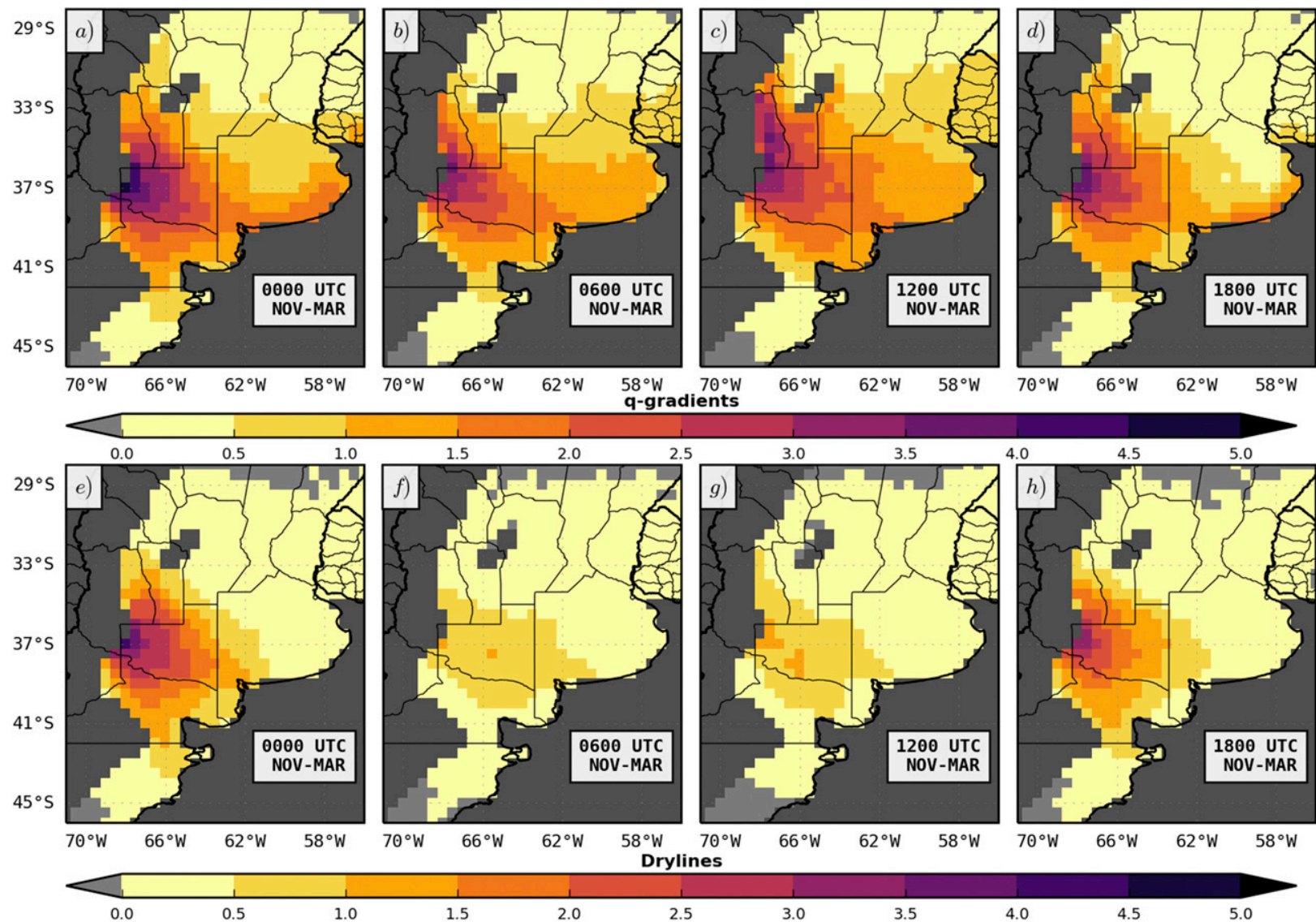

FIG. 5. Monthly number of cases in which a grid point is part of a (a)-(d) $q$-gradient and (e)-(h) dryline object for the warm season (November-March) as a function of the time of the day in the 1979-2016 period. Dark gray: grid points where the surface pressure is below $925 \mathrm{hPa}$ more than $20 \%$ of the times as well as sea masked points.

sample of at least 30 years. It is useful to look first at the number of $q$-gradient events (Figs. 5a-d) to locate preferred regions for the development of large moisture contrasts independently of their association with a dryline. The $q$-gradient objects have maximum frequencies at the Andes foothills over western La Pampa and southeast Mendoza, extending southeastwards toward the Atlantic coast. The number of these events is similar throughout the day, with a slightly higher number of events during the afternoon and evening (1800 and 0000 UTC). The summer month's maximum number of $q$-gradient events is highly coincident with the region of maximum mean frontogenesis at $850 \mathrm{hPa}$ identified by Arraut and Barbosa (2009). They showed that deformation frontogenesis was the primary source of this maximum. This mechanism can potentially explain the increase of specific humidity gradients over that area as well. Another secondary maximum of $q$-gradient events is found at 0000 UTC (Fig. 5a) and 1800 UTC (Fig. 5d) over the Atlantic coast of Buenos Aires, which could be associated with land-sea moisture differences.
Dryline events are more frequent during the warm months coincident with the main $q$-gradient maximum, extending southeastwards from southeast Mendoza toward the Atlantic (Figs. 5e-h). Unlike the $q$-gradients, dryline events exhibit a marked diurnal cycle, with much higher frequencies at 0000 and 1800 UTC than at 0600 and 1200 UTC. The maximum number of events is found over western La Pampa at 0000 UTC, with 4 drylines per month and a peak of 5.7 in January (not shown), rapidly decreasing toward the southeast. During the daytime, most of the $q$-gradient events occurring in this region can also be classified as dryline events. However, this is not the case in the nighttime. This could be the result of the contrast between the drier soil in northern Patagonia and the relatively moist soil over the CAP. This contrast leads to a larger amplitude in the temperature diurnal cycle over northern Patagonia. As a consequence, the temperature gradient points toward the dry air during the day and to the moist air during the night thus explaining the nocturnal minimum in dryline detection. Also, in some cases, the stronger cooling over northern 


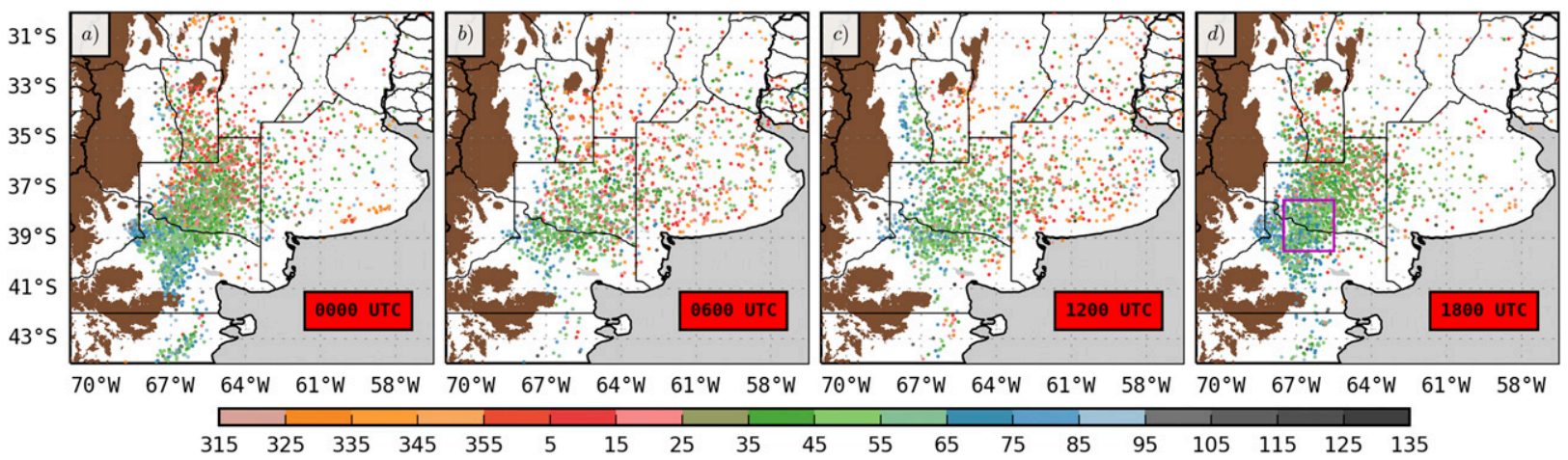

FIG. 6. Dryline centroid locations during the warm season (November-March). The colors indicate the objectwise averaged direction of $\nabla \mathbf{q}\left({ }^{\circ}\right)$ relative to the north (i.e., $0^{\circ}$ indicate a northward pointing $\nabla \mathbf{q}, 90^{\circ}$ an eastward pointing $\nabla \mathbf{q}$, etc.). Brown shading: terrain height over $1000 \mathrm{~m}$ from ETOPO1. The magenta box at 1800 UTC indicates the location of the centroids selected for the composite analysis.

Patagonia could lead to the strengthening of the temperature gradient during the night, further diminishing the probability of the moisture boundary being identified as a dryline. Previous works also acknowledge a diurnal variation in the sign of the temperature gradient across the dryline in the U.S. Great Plains, and in the sharpness of the dryline, that is better defined in the midafternoon hours than in the early morning (Schaefer 1974).

During the cold season, the frequency of dryline events diminishes dramatically (not shown). Some drylines are detected at the foothills of the Andes (between 1 and 1.5 dryline per month, mostly at 1200 and 1800 UTC), probably as a result of lee subsidence and its associated drying, which may contribute to locally generated large humidity contrasts close to the Andes. Overall over the rest of the domain, the number of dryline days per month is less than 0.5 and this number does not show a significant diurnal cycle.

\section{b. Characterization of drylines in Argentina}

For a brief characterization of the drylines, some parameters are computed and examined for all the objects during the warm season, which is the period with the higher frequency of these events. Figures 6 and 7 show the position of the centroids of the dryline objects, along with the object-wise average of $\nabla \mathbf{q}$ direction (Fig. 6) and their size (Fig. 7) at 0000, 0600, 1200, and 1800 UTC. Dryline size is computed as the sum of the area associated with each of the grid points in a particular object, which in turn is a function of latitude. These figures confirm that dryline occurrence has a strong diurnal cycle with most of the drylines being detected at 1800 and 0000 UTC (1500 and 2100 LT, respectively). Moreover, drylines detected at 0000 and 1800 UTC are larger and mainly oriented in the NW-SE direction.

In Figs. 6 and 7, it is evident that the drylines show different characteristics when their centroids are located on the Andes foothills or farther east over the CAP. The former are smaller objects (Fig. 7), oriented roughly parallel to the topography (Fig. 6), while the latter are larger and their moisture gradients are mainly northeasterly oriented. Examination of the joint distribution of averaged $\nabla \mathbf{q}$ direction, averaged $\nabla \mathbf{q}$ intensity, and object size (not shown) makes it clear that the larger drylines are the ones with the most intense mean specific humidity gradients. Also, the direction of the moisture

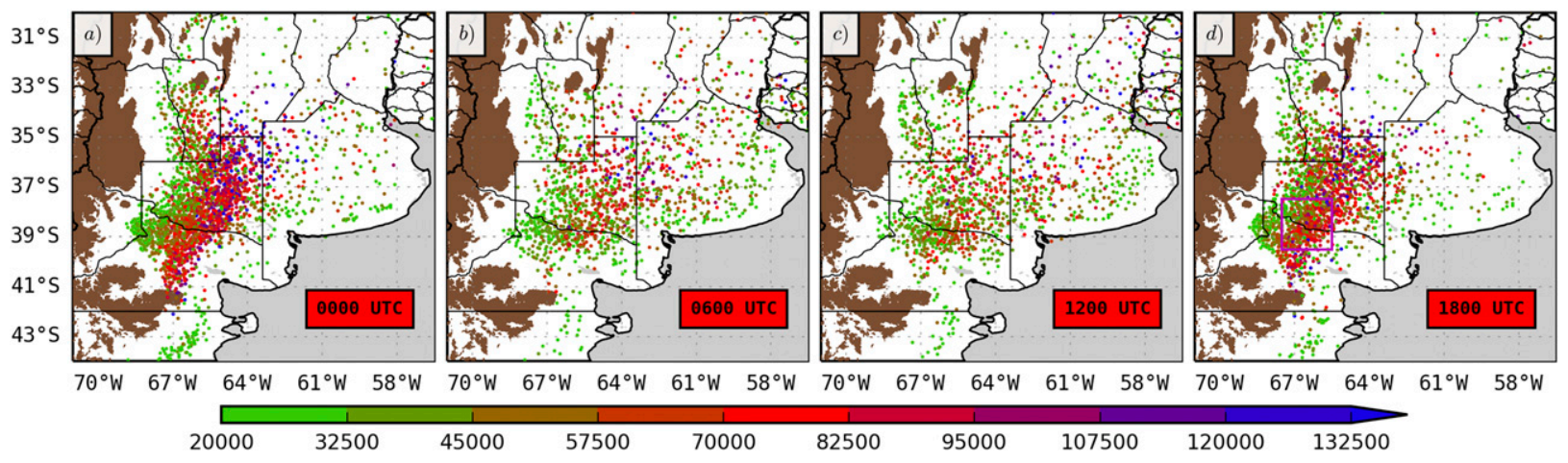

FIG. 7. As in Fig. 6, but with the colors indicating the dryline size $\left(\mathrm{km}^{2}\right)$. 
gradient for these large drylines tends to fall in the northeast quadrant, corresponding to objects with a NW-SE orientation.

It is also noteworthy that some centroids located farther away from the area of maximum dryline density are more frequently detected at 0600 and 1200 UTC. Examination of some particular cases revealed that these objects are contiguous regions of strong low-level moisture gradient in which the temperature gradient is either weak or is pointing toward the dry air. Some of these objects correspond to long-lived drylines that originated in northern Patagonia which propagates toward the northeast, while others are associated with former cold fronts that became stationary over land, diminishing their thermal gradients. The second case represents roughly $10 \%$ of the cases detected in this area. Since in these cases the objects seem to be associated with the latter stages of a classical front, they are considered as false detections of the objective algorithm.

\section{Mechanisms associated with dryline formation}

\section{a. Synoptic and mesoscale circulation associated with drylines}

To analyze favorable environments and the physical processes that lead to the dryline formation in central Argentina, composite analysis over a group of cases is performed. Given that the drylines detected in the climatology can be associated with different mechanisms, in this work, we focus on the physical processes associated with the genesis and evolution of large and intense drylines detected in the area of maximum frequency. These drylines are oriented roughly in the same direction, and the spatial density of their centroids maximizes between CAP and NPP. We select large drylines that took place in this region during January, the month of maximum frequencies, to generate composites for the spatiotemporal evolution of different variables associated with these events. To produce a subset of drylines with similar characteristics, drylines detected at 1800 UTC with centroids located within the box indicated in Fig. 6d are selected. Also, the drylines are required to have an object-wise averaged $\nabla \mathbf{q}$ direction between $30^{\circ}$ and $80^{\circ}$, and an object size of at least 20 grid points. A total of 74 dryline events were detected that meet all the required characteristics.

While drylines are more frequently detected at 0000 UTC, a large fraction of those drylines was already formed by 1800 UTC. At 1800 UTC it is furthermore less likely that drylines and the surrounding environment are affected by summertime afternoon convection, which is sometimes the case at 0000 UTC. Therefore 1800 UTC is thought to be a more adequate time to study the processes that lead to dryline development. The small region selected and the restriction imposed on the dryline orientation ensures that this subset consists of objects with similar locations and characteristics, thus making it appropriate to perform a composite analysis. Other composites constructed considering slightly different regions, with drylines detected at 0000 UTC, and over different summer months were produced, and the results were essentially the same, showing that the composites are not strongly sensitive to these aspects (not shown).

For each dryline in this subset, the fields of specific humidity, temperature, wind components, and geopotential height between $12 \mathrm{~h}$ before and $6 \mathrm{~h}$ after the event are considered. These fields are then averaged over the sample, and the standardized anomalies with respect to the January climatology (1979-2016) are calculated. The terms of the thermodynamic and water vapor conservation equations are computed individually for each event and time before being averaged over the sample.

Figures 8 and 9 show the composite mean and anomalies for different variables at the dryline detection time (1800 UTC). The strong moisture gradient associated with drylines extends southeastwards from the foothills of the Andes in southern Mendoza, reaching the shores of the Atlantic Ocean (Fig. 8a), coinciding with the axis of dilatation of a confluent low-level circulation. Moist anomalies in excess of 1.5 standard deviations are found northeast of the boundary and weaker dry anomalies to the southwest. The $925 \mathrm{hPa}$ temperature field shows a thermal ridge south of the dryline, with warm anomalies of about $0.8 \sigma$ over land, extending toward the ocean (Fig. 8b). The thermal gradient across the dryline is then the opposite of what is expected in a surface front and clearly separates the dryline from the zone of maximum baroclinicity that remains farther south and over the high terrain. This baroclinic zone is associated with an advancing cold front that is preceded by the occurrence of the dryline, as described by Lichtenstein and Schwarzkopf (1966), and shown for example in Fig. 2.

The $1000 \mathrm{hPa}$ field (Fig. 9a) shows negative geopotential anomalies over most of the domain and, in particular, a trough associated with the dryline, with maximum cyclonic anomalies well collocated with the warm anomalies at $925 \mathrm{hPa}$, suggesting that this trough has, at least partially, a thermal origin. The circulation associated to this thermal trough reinforces low-level confluence over the dryline, contributing to its intensification. At upper levels (Fig. 9b), the jet stream is located south over Patagonia and there are cyclonic anomalies upstream and anticyclonic downstream of the continent, suggesting that most of the drylines selected for the composite analysis occur during strong synoptic 

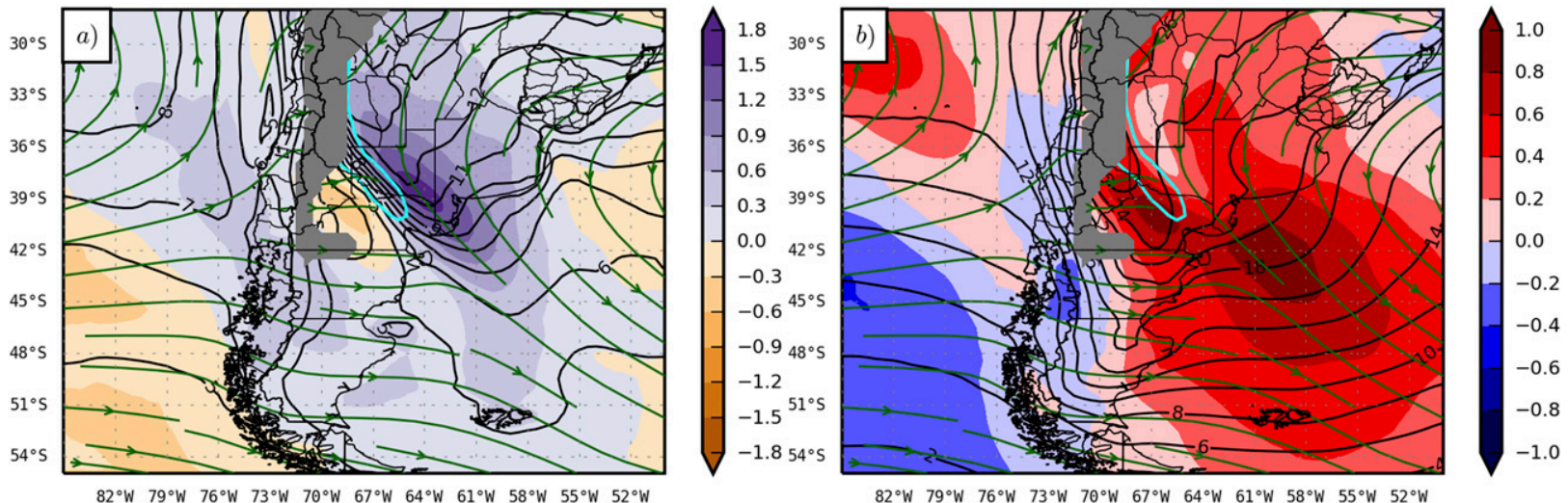

FIG. 8. Composite mean (contours) and standardized anomaly with respect to the January climatology (shaded) at the time of detection of the dryline (1800 UTC) for (a) specific humidity $\left(\mathrm{g} \mathrm{kg}^{-1}\right)$ and (b) temperature $\left({ }^{\circ} \mathrm{C}\right)$ at $925 \mathrm{hPa}$, with streamlines at the same level. The cyan contour encloses the region of $\nabla \mathbf{q}$ magnitude larger than $3 \mathrm{~g} \mathrm{~kg}^{-1} 100 \mathrm{~km}^{-1}$ associated with the dryline. The gray shade indicates grid points in which the model terrain height is over $1000 \mathrm{~m}$.

forcing. Although the classification of environments with strong versus weak synoptic conditions may be subjective, a quick examination of the cases showed that indeed most of the cases were found to be in association with an approaching upper-level trough and its associated surface cold front.

The general pattern described in Figs. 8 and 9 is expected when describing the favorable conditions for the advance of a cold front in the region. This is, an approaching upper-level trough, a confluent low-level circulation accompanied by a surface trough, and a moisture discontinuity. However, the resultant crossboundary thermal gradient has a poleward-directed component. This particular feature is what allows us to differentiate this boundary from a cold front, and classify it as a dryline.

In the following section, the processes leading to the intensification of the low-level moisture gradient as well as the development of the thermal ridge that helps to decouple the moisture and temperature gradients are analyzed based on the composites.

\section{b. Physical processes for dryline development}

Figures 10 and 11 show the evolution of the $925 \mathrm{hPa}$ specific humidity and potential temperature, respectively, along with the local tendencies from 0600 to 0000 UTC. As in Figs. 8 and 9, the region where the magnitude of $\nabla \mathbf{q}$ at $925 \mathrm{hPa}$ is larger than $3 \mathrm{~g} \mathrm{~kg}^{-1}$ $(100 \mathrm{~km})^{-1}$ in the composites is enclosed by a red contour and is used to indicate the area where the magnitude of $\nabla \mathbf{q}$ is stronger.

In some of the cases included in the composite, areas of strong $\nabla \mathbf{q}$ could not be flagged as drylines (following the criteria used in this work) over the $12 \mathrm{~h}$ previous to the detection. However, continuous strengthening of the low-level moisture gradient is observed during these

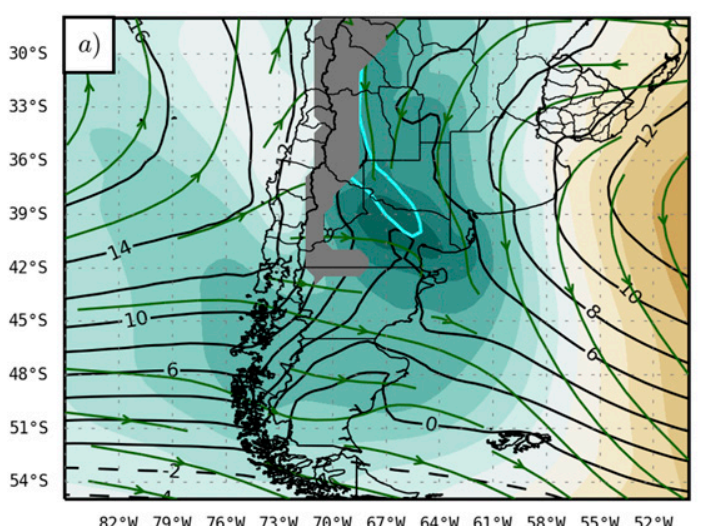

$79^{\circ} \mathrm{W} 76^{\circ} \mathrm{W} 73^{\circ} \mathrm{W} 70^{\circ} \mathrm{W} 67^{\circ} \mathrm{W} 64^{\circ} \mathrm{W} 61^{\circ} \mathrm{W} 58^{\circ} \mathrm{W} 55^{\circ} \mathrm{W} 52^{\circ} \mathrm{W}$
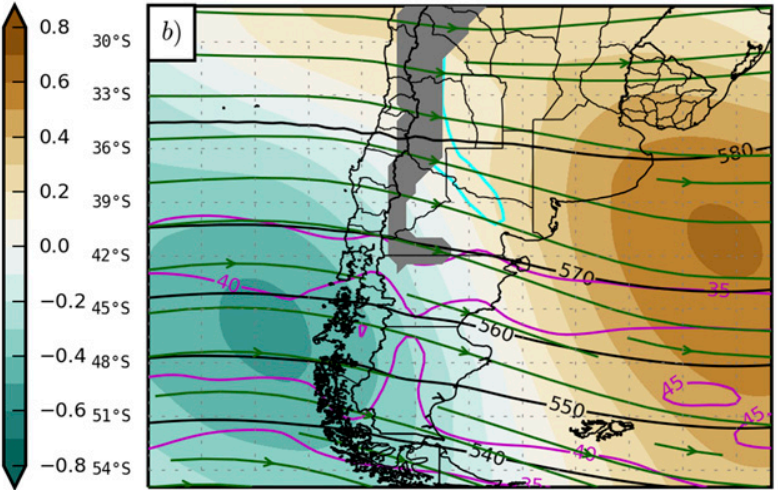

$82^{\circ} \mathrm{W} 79^{\circ} \mathrm{W} 76^{\circ} \mathrm{W} 73^{\circ} \mathrm{W} 70^{\circ} \mathrm{W} 67^{\circ} \mathrm{W} 64^{\circ} \mathrm{W} 61^{\circ} \mathrm{W} 58^{\circ} \mathrm{W} 55^{\circ} \mathrm{W} 52^{\circ} \mathrm{W}$

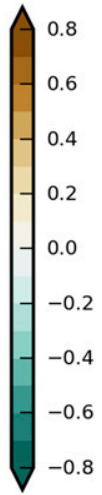

0.8

FIG. 9. As in Fig. 8, but for geopotential height (dam) at (a) 1000 and (b) $500 \mathrm{hPa}$. Magenta contours: isotachs at $500 \mathrm{hPa}$ $\left(\mathrm{kt} ; 1 \mathrm{kt} \approx 0.5144 \mathrm{~m} \mathrm{~s}^{-1}\right)$. 


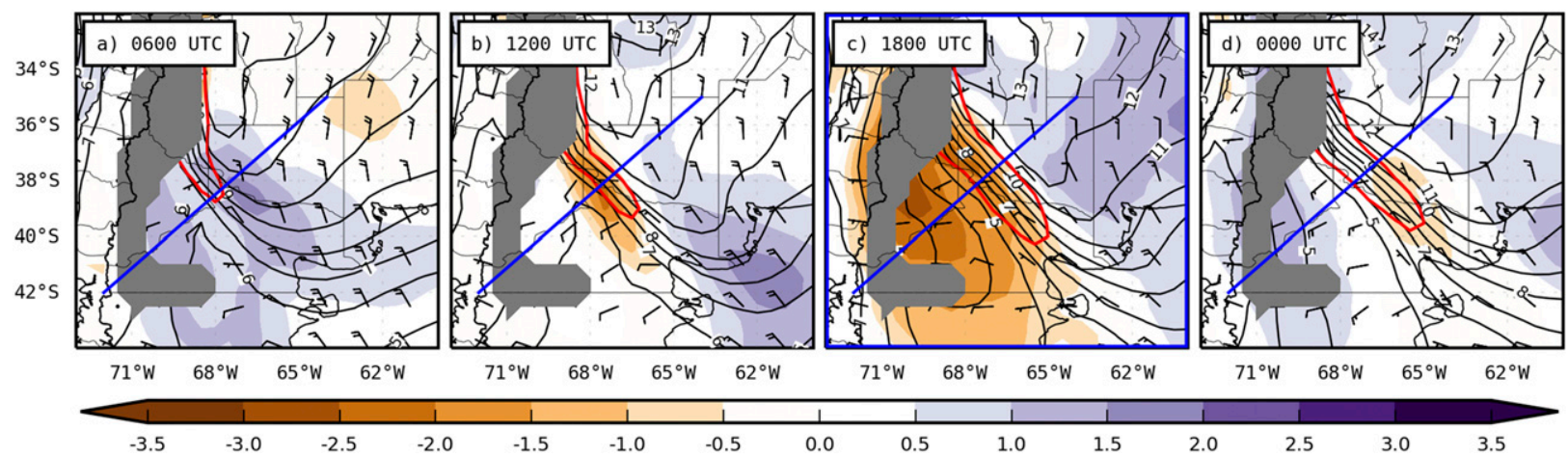

FIG. 10. Composites of specific humidity (contours, $\mathrm{g} \mathrm{kg}^{-1}$ ), its tendency [shaded, $\mathrm{g} \mathrm{kg}^{-1}(6 \mathrm{~h})^{-1}$ ], and wind (kt) at $925 \mathrm{hPa}$ at (a) 0600 , (b) 1200 , (c) 1800 , and (d) 0000 UTC. The contour of $\nabla \mathbf{q}$ equal to $3 \mathrm{~g} \mathrm{~kg}^{-1}(100 \mathrm{~km})^{-1}$ is included in red. The blue lines indicate the location of the cross sections shown in Fig. 13.

hours. The area of stronger low-level $\nabla \mathbf{q}$ is initially located to the lee of the Andes (Fig. 10a) and intensifies and expands toward the southeast reaching its maximum extension at 1800 UTC (Fig. 10c). Over this period the area of strong $\nabla \mathbf{q}$ is approximately aligned with the axis of dilatation of a confluent wind field with north and northwest flow on the moist side and west and southwest on the dry side, which contributes to its intensification.

At 0600 UTC there is generalized low-level moistening over the region, associated with strong moist advection north of the area with strong $\nabla \mathbf{q}$ (Fig. 10a). At this time, the temperature over the NPP is decreasing rapidly (Fig. 11a), as a consequence of the combination of the nocturnal radiative cooling and cold advection (as will be shown more in detail in the following section). Later, at 1200 UTC (Fig. 10b), the propagation of the maximum moisture advection to the southeast contributes to the extension of the area of strong $\nabla \mathbf{q}$ in that direction. Additionally, strong drying south of that area contributes to further intensifying the low-level $\nabla \mathbf{q}$. Low-level diabatic and advective cooling continues over most of the domain, although with lower magnitude (Fig. 11b). Both at 0600 and 1200 UTC, there is a welldefined baroclinic zone, oriented in a northwest to southeast direction, with its leading edge relatively close to the area of maximum $\nabla \mathbf{q}$, but slightly south of its associated wind shift.

At 1800 UTC, a strong drying effect is denoted to the south and over the dryline, while moistening continues to the north strengthening the dryline contrast (Fig. 10c). At the same time, a rapid temperature increase is observed over the arid and elevated terrain of the NPP (Fig. 11c) which, as will be shown later, is mainly associated with diurnal heating and turbulent mixing. This warming leads to the reversal of the acrossdryline temperature gradient, as a broad thermal ridge develops south of the dryline. This feature helps to propagate the area of maximum baroclinicity to the south and southwest, over the higher terrain, significantly increasing the distance between the baroclinic zone and the dryline. The thermal ridge remains visible at 0000 UTC (Fig. 11d), although cold air starts to

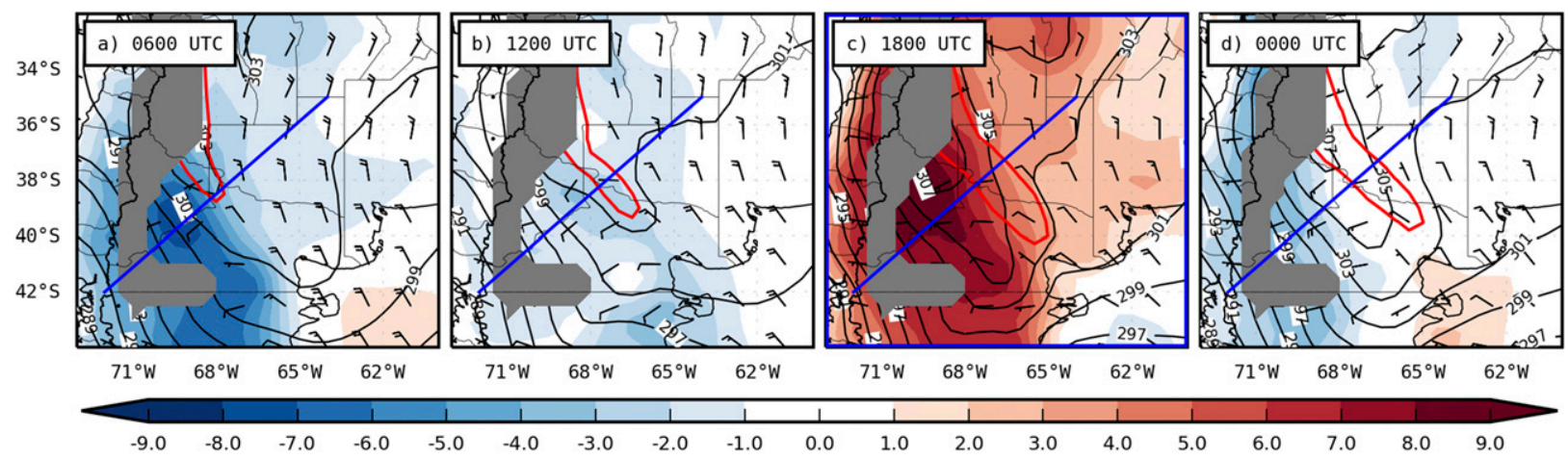

FIG. 11. Composites of potential temperature (contours, K), its tendency [shaded, K $(6 \mathrm{~h})^{-1}$ ], and wind (kt) at $925 \mathrm{hPa}$ at (a) 0600 , (b) 1200 , (c) 1800 , and (d) 0000 UTC. The contour of $\nabla \mathbf{q}$ equal to $3 \mathrm{~g} \mathrm{~kg}^{-1}(100 \mathrm{~km})^{-1}$ is included in red. The blue lines indicate the location of the cross sections shown in Fig. 14. 

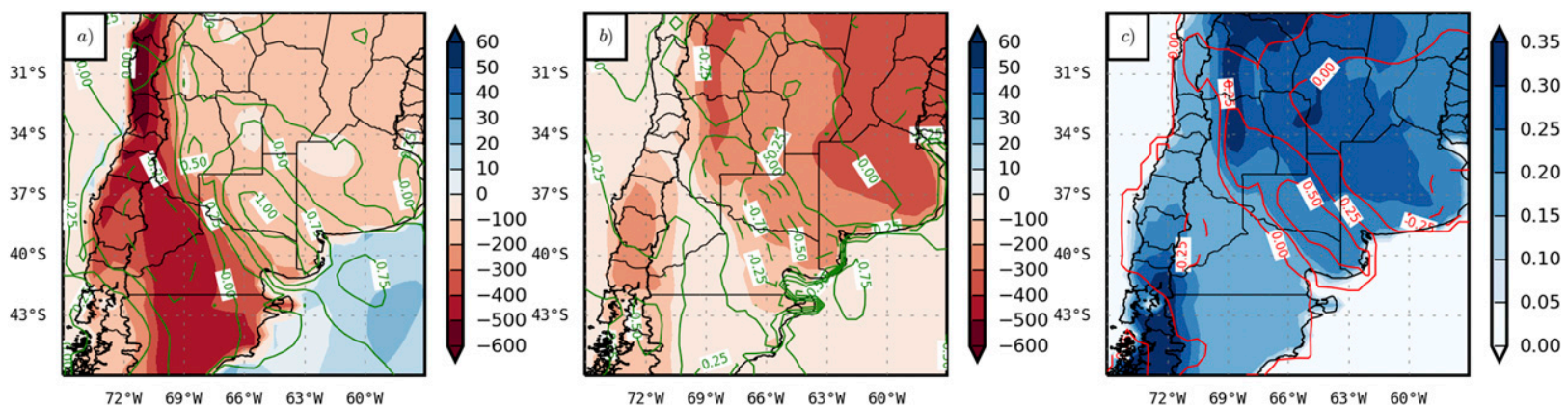

FIG. 12. As in Fig. 8, but for (a) surface downward sensible heat flux $\left(\mathrm{W} \mathrm{m}^{-2}\right)$, (b) surface downward latent heat flux $\left(\mathrm{W} \mathrm{m}{ }^{-2}\right)$, and (c) volumetric soil water in the first $7 \mathrm{~cm}$ layer (unitless). Composite mean (shaded) and standardized anomaly with respect to the January climatology (contours).

advance toward the dryline, as a result of cooling over the topography and increased westerly and southwesterly winds. At this time, the intensity of the moisture gradient starts to decrease, owing to slight drying on its northeastern side (Fig. 10d).

Overall, during the period considered in Figs. 10 and 11, the area of strong $\nabla \mathbf{q}$ associated to drylines detected at 1800 UTC shows a northeastward propagation. Some particular cases of long-lived drylines (i.e., drylines detected at all times between 0000 and 1800 UTC) belonging to the sample were studied separately, to draw some hypotheses about the diurnal movement of the dryline. We found that some drylines show a characteristic diurnal cycle, retroceding toward the NPP between 0000 and 0600 UTC, and then advancing toward the CAP at 1200 UTC, further advancing at 1800 UTC or becoming stationary in some cases. This movement is similar to the one observed in the U.S. drylines under synoptically quiescent conditions, where the drylines show an eastward motion during the day and westward retreat at night (Schaefer 1986; Markowski and Richardson 2010). Other long-lived drylines showed a continued northeastward propagation.

Figures 10 and 11 suggest that daytime turbulent mixing plays a significant role in dryline formation. Inhomogeneities in low-level temperature and moisture tendencies associated with boundary layer processes significantly contribute to the formation of the dryline. To investigate the source of these inhomogeneities, Fig. 12 shows the distribution of surface sensible and latent heat fluxes. South of the dryline heat (moisture) fluxes are larger (smaller) with respect to fluxes north of the dryline (Figs. 12a,b). This distribution is related to differences in the vegetation cover between these two regions (not shown), and the distribution of soil moisture (Fig. 12c) which is larger over CAP allowing for more evapotranspiration. While climatological soil moisture is lower over NPP with respect to CAP, the composite shows that dryline cases are associated with a positive anomaly in soil moisture over southern CAP which contributes to decreased (increased) heat (moisture) fluxes over that area, and the intensification of the dryline (Figs. 12a,b). This soil moisture positive anomaly is oriented in the same direction as the dryline, and increases in magnitude continuously during the day (not shown), suggesting that rainfall and clouds are present on the moist side of the dryline on some of the cases thus contributing to enhancing differences in heat surface flux across the dryline.

To evaluate the relative importance of the above mentioned processes and the role of topography in the generation of the dryline and the thermal ridge that forms over NPP, vertical cross sections of specific humidity and potential temperature, their tendency, and the contribution of the terms on the rhs of Eqs. (1) and (2) between 0600 and 0000 UTC are shown in Figs. 13 and 14, respectively. The cross sections are oriented across the dryline, as indicated in Figs. 10 and 11. As in these figures, the red contour indicates regions where the $\nabla_{p} \mathbf{q}$ is larger than $3 \mathrm{~g} \mathrm{~kg}^{-1}(100 \mathrm{~km})^{-1}$.

At 0600 UTC the area with strongest moisture gradients is relatively small and shallow. There is a generalized low-level moistening, mostly explained by the previously discussed horizontal advection term (Fig. 13b). Midlevel drying is observed on the lee side of the Andes generating an area of dry air aloft (ADAA) (Fig. 13a). This drying is produced by subsidence over the lee of the Andes of air originated above the top of the Pacific Ocean maritime boundary layer (Fig. 13c). The ADAA is embedded in a westerly current that contributes to its eastward propagation (Fig. 13b). At this time the residual term is smaller with respect to the others (Fig. 13d) and is associated with moistening to the lee of the Andes and low-level drying to the west of the ADAA.

In the temperature field at 0600 UTC, a baroclinic zone is clearly observed over the Andes slopes (Fig. 11a), 


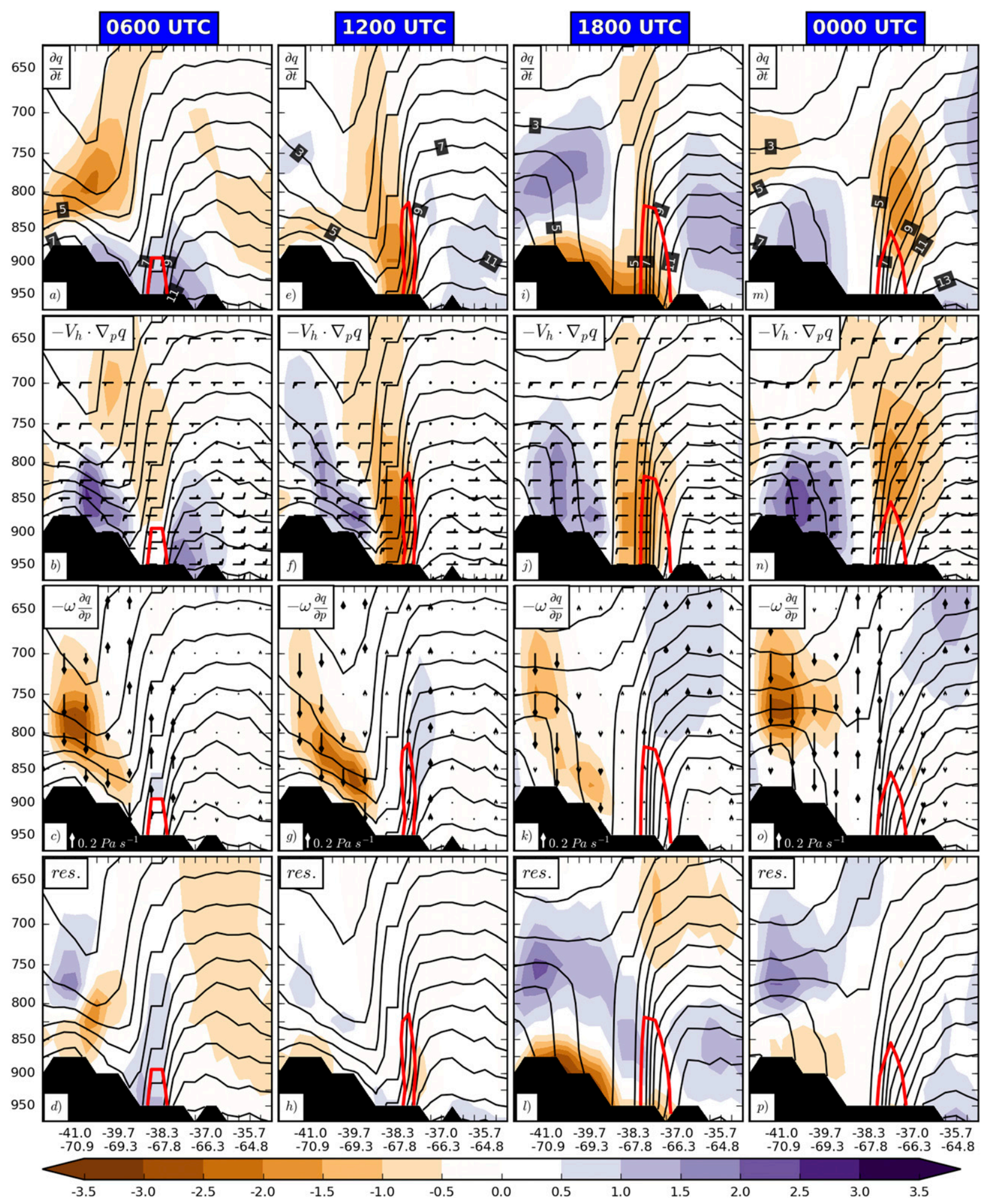

FIG. 13. Cross sections along the blue lines in Fig. 10 showing composites of specific humidity (contours, $\mathrm{g} \mathrm{kg}^{-1}$ ) and terms of the water vapor conservation equation [shaded, $\mathrm{g} \mathrm{kg}^{-1}(6 \mathrm{~h})^{-1}$ ] at (a)-(d) 0600, (e)-(h) 1200, (i)-(1) 1800, and (m)-(p) 0000 UTC. The red contour highlights the $3 \mathrm{~g} \mathrm{~kg}^{-1}(100 \mathrm{~km})^{-1}$ isoline of the $\nabla_{p} \mathbf{q}$. Barbs indicate the in-plane wind $(\mathrm{kt})$ and arrows the vertical velocities $\left(\mathrm{Pa} \mathrm{s}{ }^{-1}\right)$. 


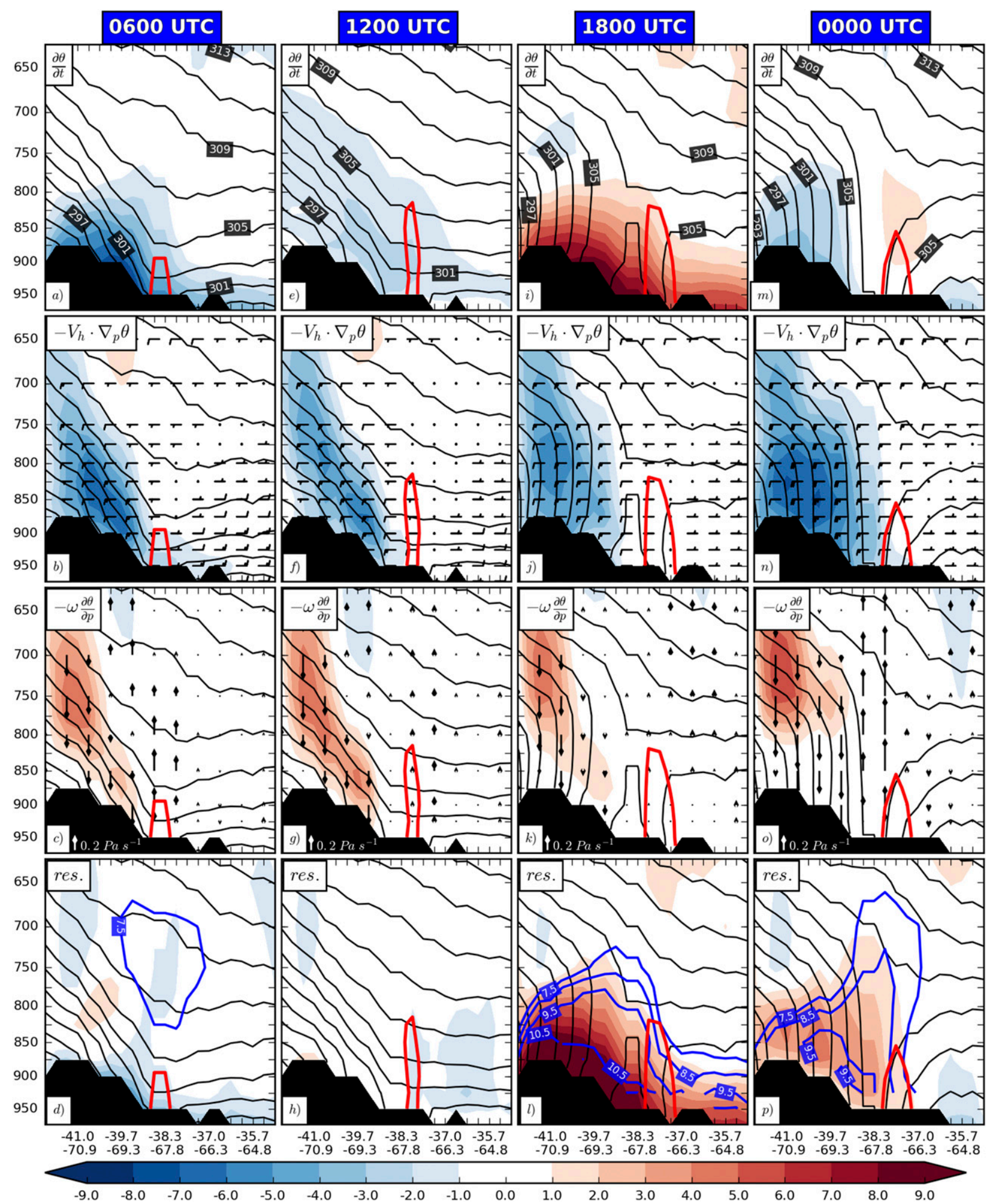

FIG. 14. As in Fig. 13, but for potential temperature and terms in the thermodynamic equation. The blue contours in (d), (h), (l), and (p) indicate the vertical lapse rate of temperature at $1 \mathrm{~K} \mathrm{~km}^{-1}$ interval, starting at $7.5 \mathrm{~K} \mathrm{~km}^{-1}$. 
which is associated with cold advection (Fig. 14b). Cold advection is partially compensated by subsidence warming to the lee of the Andes (Fig. 14c), reducing the speed at which the baroclinic zone propagates to the east. The residual term is mainly associated with low-level radiative cooling (Fig. 14d).

Six hours later, at 1200 UTC, there is a marked increase in the magnitude and depth of the low-level humidity gradient, owing mainly to strong drying south of the dryline (Fig. 13e). This drying is caused by a downward extension of the lee subsidence that propagates the ADAA toward lower levels (Fig. 13g). This downward propagation of the ADAA significantly enhances dry horizontal advection immediately to the east of the Andes foothills over the NPP. It also contributes to increasing the magnitude of the moisture vertical gradient over the foothills (Fig. 13f). At this time the contribution of the residual term is relatively small (Fig. 13h).

The potential temperature change at this time is mainly characterized by a weak low to midlevel cooling to the lee of the Andes (Fig. 14e). This weak cooling emerges from the partial compensation between strong cold advection and subsidence warming (Figs. 14f,g), resulting in a nearly stationary baroclinic zone. The slow propagation of the baroclinic zone keeps it away from the maximum horizontal confluence, thus delaying frontogenesis (Fig. 11b). The role of the diabatic term at this time is nearly negligible (Fig. 14h).

At 1800 UTC the cross section shows the development of a well-mixed boundary layer whose vertical extent can be determined from the moisture and potential temperature distributions (Figs. 13i and 14i). The boundary layer is deeper behind the dryline where the stronger surface heat fluxes are found (Fig. 12a). The residual term (Fig. 131) contributes to generating lowlevel drying, particularly over the plateau on the dry side of the dryline and moistening near the top of the boundary layer. This drying/moistening pattern is consistent with moisture redistribution in a convectively unstable boundary layer driven by strong surface heating. The near-surface drying associated with the development of the boundary layer can be due to the relatively smaller surface moisture flux to the south of the dryline over NPP, and also due to the entrainment of dry air from the ADAA at the top of the boundary layer. North of the dryline, the residual term contributes to increasing moisture through the depth of the boundary layer as a result of the stronger surface moisture flux (Fig. 12b). Low to midlevel dry air is then advected toward the northeast by the horizontal flow (Fig. 13j), leading to the broadening and intensification of the dryline, which is now located just south of the low-level confluence (Fig. 13j). At this time, vertical advection continues to reduce moisture to the lee of the Andes (Fig. 131). However, the dryline is located farther northeast due to the combined effect of mixing and horizontal advection.

During this time the potential temperature field undergoes fast changes, with strong low-level heating, and the development of the thermal ridge south of the dryline (Fig. 14i). This is mainly associated with the turbulent heat flux convergence which is stronger on the dry side of the dryline (Fig. 14l) due to the larger surface heat fluxes (Fig. 12a). Cold horizontal advection continues to act over the topography (Fig. 14j), but its effect is to a large extent compensated by vertical advection (Fig. 14k). The low-level warming associated with diurnal heating produces a low-level back propagation of the baroclinic zone to the south and southwest, thus increasing the gap between the baroclinic zone and the dryline.

At 0000 UTC, dry horizontal advection, which is stronger in the upper portion of the boundary layer, tilts the dryline toward the moist air (Figs. 13m,n). Stronger low-level cold horizontal advection (Fig. 14n) starts to overcome the warm vertical advection (Fig. 14o) and the diabatic warming on the dry air mass (Fig. 14p), so the baroclinic zone starts to advance toward the plains (Fig. 14m). An interesting feature that appears at this time is a layer of decreased static stability located over and slightly to the east of the zone of maximum moisture contrast. The origin of this unstable layer can be traced back to the upper part of the deep boundary layer that developed earlier over the higher terrain (Figs. 14l-p). An examination of the same cross section for all the events used to compute the composite reveals that this signature is associated with some events (roughly $30 \%$ of the cases) in which the deep afternoon boundary layer is advected over the relatively shallow boundary layer that develops over the plains leading to the formation of an elevated mixed layer.

A direct vertical circulation develops at 0000 UTC, with ascent over the thermal ridge and over the dry edge of the dryline, and weak descent at low levels over the moist air (Figs. 13-14o). This vertical circulation could be forced by the horizontal gradient of heating across the dryline, a mechanism known as the "inland seabreeze" (Sun and Ogura 1979). Another direct vertical circulation is found with ascents on the leading edge of the advancing cold air, and descents associated with cold advection behind.

Hours later, the baroclinic zone starts moving toward the plains faster than the high moisture contrast zone eventually leading to the merging of the two (not shown), a process well documented in the U.S. drylines and other parts of the world (Neiman and Wakimoto 1999; Qin and Chen 2017). Thus, the low-level 
distribution of moisture, temperature and the low-level circulation becomes consistent with the advance of a surface cold front.

\section{Summary and conclusions}

In this work, an automated algorithm for dryline detection based on reanalysis data is formulated and successfully implemented to generate a climatology of these features in central Argentina. The application of this algorithm to 38 years of reanalysis data shows that drylines are a common feature of the warm season in Argentina, with higher frequencies in between the NPP and the CAP, and increasing toward the Andes. Peaks of 4 drylines per month in the warm season $(\sim 13 \%$ of the days from November to March) and up to 5.7 in January ( $\sim 19 \%$ of the days) are found in western La Pampa and southern Mendoza, showing that drylines in that region have lower frequencies than the ones that develop in the U.S. Great Plains. The region of maximum dryline frequency coincides with the southern border of continental deep moist convection during the warm season. The dry air mass associated with the westerly flow that plays a fundamental role in the formation of drylines in central Argentina, seems to be contributing to limit the southward extent of the continental convection as has been previously studied by Chou and Neelin (2001). Analysis of the drylines found in the warm season also shows that, in general, the larger drylines are the ones with the most intense specific humidity gradient that tend to point in a northeast direction.

Composite analysis of selected drylines with similar characteristics over the month of January allows us to identify the typical synoptic setting associated with them and to schematize the conceptual model shown in Fig. 15. Drylines develop in between a moist and warm air mass that positions over central and northern Argentina and a dry and warm air mass located to the south, over northern Patagonia. This boundary is located in a region of thermally driven negative low-level geopotential anomalies and coincides with the axis of deformation of a confluent low-level circulation, with anticyclonic northerly and northwesterly flow to the north and westerlies and southwesterlies to the south. A thermal ridge develops south of the dryline in response to strong surface heating over the NPP, contributing to a poleward-directed cross-boundary thermal gradient. This feature also helps to decouple the regions of strong moisture and temperature gradients.

The water vapor conservation and thermodynamic equations applied to the dryline environment help to understand the processes that lead to the origin of the strong moisture gradient at the dryline and of the thermal

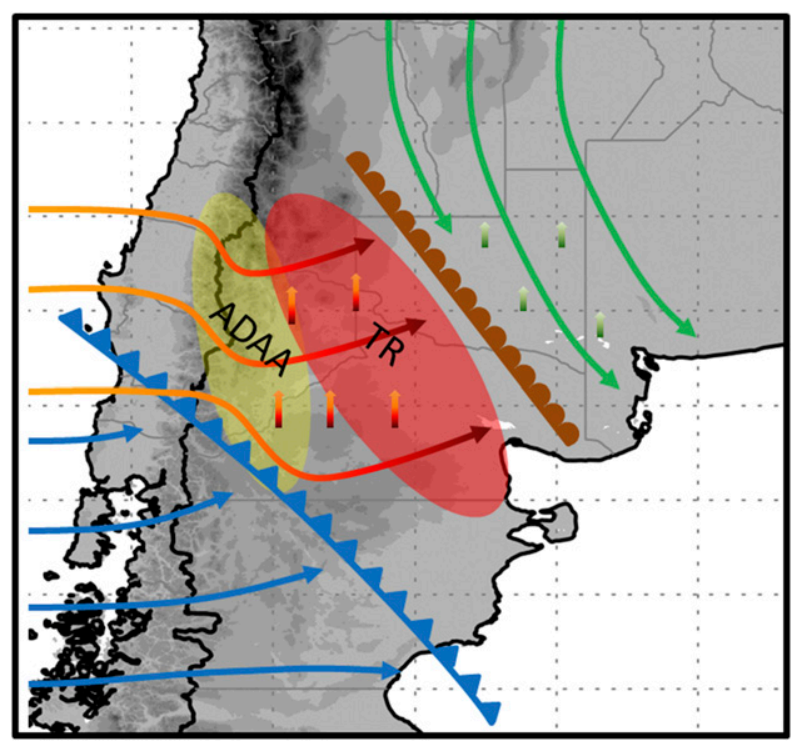

FIG. 15. Conceptual model of a dryline in central Argentina. The dryline and cold front are represented by the usual symbols. Green streamlines indicate the moist air moving from the north in an anticyclonic circulation, and increasing its moisture content due to the effect of evapotranspiration (upward pointing green arrows). Yellow to red streamlines indicate air moving from on top of the Pacific Ocean boundary layer that experiences lee subsidence over the southern Andes and creates an area of dry air aloft (ADAA). This dry air propagates toward central Argentina, and strong surface sensible heat fluxes (upward pointing red arrows) promote the development of a well-mixed boundary layer where dry air is entrained. A thermal ridge (TR) also develops south of the dryline in response to the strong surface heating and contributes to separate it from the cooler air associated with the cold front (blue streamlines).

ridge that permits to differentiate it from a cold front. On one hand, a moist and warm air mass is advected by anticyclonic northerly and northwesterly flow over central Argentina, and its low-level moisture content seems to be slightly increased by evapotranspiration into the vegetated CAP. On the other hand, the dry air south of the dryline has its origin on top of the southeastern Pacific maritime boundary layer. Driven by westerly winds, this air mass crosses the southern Andes and experiences lee subsidence, which creates an area of dry air aloft (ADAA). This ADAA propagates eastward and northeastwards over the NPP, where the strong surface heating and vertical mixing during the afternoon allow it to reach the surface. A cyclonic circulation develops over the NPP, related to this heating and an approaching upperlevel disturbance, and together with the anticyclonic circulation to the north generates a confluent pattern, strongly frontogenetic for the humidity field, that finally narrows into a dryline. The subsidence at the lee of the Andes and surface heating over the NPP also contributes to delay the displacement of the baroclinic zone. 
It is important to note that the conceptual model that is shown in Fig. 15 only applies to large drylines that form over northern Patagonia during the summer, and more work is needed to fully understand all of the possible mechanisms that lead to dryline formation in central Argentina.

The cross sections of the fully developed dryline in Figs. $13 \mathrm{i}$ and $14 \mathrm{i}$ result very similar to those found in the literature on the U.S. Great Plains drylines. Examples are found in Figs. 23.10-23.12 of Schaefer (1986), Fig. 10 in Carlson et al. (1983) among others. In this last figure, the presence of a thermal ridge between the dryline and the cooler air associated with a cold front to the west and the vertical orientation of the isohumes at the dryline becomes evident. A case by case analysis reveals that roughly $30 \%$ of large drylines formed over northern Patagonia exhibit an EML on top of the moist boundary layer, particularly during the evening hours. The relatively low fraction of events associated with an EML in our study is consistent with the previous study by Ribeiro and Bosart (2018) and might be related to the limited vertical resolution of the reanalysis data and the known difficulties of numerical weather prediction models to represent highly stable layers (Sandu et al. 2013). Additionally, the wider extent of the Rockies Mountains may favor the higher frequencies of EMLs associated with drylines in the U.S. Great Plains, when compared with the ones found in this study.

Future work is required to gain a more comprehensive understanding of drylines in southern South America. The role of drylines in convection initiation over northern Patagonia and central Argentina and possible feedbacks between mesoscale circulations and drylines remains an open question. More work is also required to characterize the mechanisms involved in the displacement of drylines under different large-scale circulation conditions. The lack of a dense surface observation network is one of the major challenges for the study of drylines in this part of the world. Future studies should focus on the analysis of drylines based on additional in situ observations and remote sensing data, in order to confirm some of the processes that have been investigated in this work.

Acknowledgments. The authors thank the editor, two anonymous reviewers and Rene Garreaud for their constructive and insightful suggestions to improve the manuscript. This research was supported by the PICT 2013-1299, PICT 2014-1000, PICT 2017-0221, PICT 2017-2233, UBACyT 20020130100618BA, UBACуT 20020170100164BA, and UBACyT20020170100504BA projects.

\section{REFERENCES}

Akter, N., and K. Tsuboki, 2017: Climatology of the premonsoon Indian dryline. Int. J. Climatol., 37, 3991-3998, https://doi.org/ 10.1002/joc. 4968 .

Amante, C., and B. Eakins, 2016: ETOPO1 1 arc-minute global relief model: Procedures, data sources and analysis. NOAA Tech. Memo. NESDIS NGDC-24, National Oceanic and Atmospheric Administration, National Environmental Satellite, Data, and Information Service, National Geophysical Data Center Marine Geology and Geophysics Division, 25 pp., https://www.ngdc.noaa.gov/mgg/global/relief/ETOPO1/docs/ ETOPO1.pdf.

Anthes, R. A., Y.-H. Kuo, S. G. Benjamin, and Y.-F. Li, 1982: The evolution of the mesoscale environment of severe local storms: Preliminary modeling results. Mon. Wea. Rev., 110, 1187-1213, https://doi.org/10.1175/1520-0493(1982)110<1187: TEOTME $>2.0 . \mathrm{CO} ; 2$

Arnup, S. J., and M. J. Reeder, 2007: The diurnal and seasonal variation of the northern Australian dryline. Mon. Wea. Rev., 135, 2995-3008, https://doi.org/10.1175/MWR3455.1.

Arraut, J. M., and H. M. J. Barbosa, 2009: Large scale features associated with strong frontogenesis in equivalent potential temperature in the South American subtropics east of the Andes. Adv. Geosci., 22, 73-78, https://doi.org/10.5194/adgeo-22-73-2009.

Carlson, T. N., S. G. Benjamin, G. S. Forbes, and Y.-F. Li, 1983: Elevated mixed layers in the regional severe storm environment: Conceptual model and case studies. Mon. Wea. Rev., 111, 1453-1474, https://doi.org/10.1175/1520-0493(1983) $111<1453$ :EMLITR $>2.0$. CO;2.

Chou, C., and J. D. Neelin, 2001: Mechanisms limiting the southward extent of the South American summer monsoon. Geophys. Res. Lett., 28, 2433-2436, https://doi.org/10.1029/ 2000GL012138.

Clark, A. J., A. MacKenzie, A. McGovern, V. Lakshmanan, and R. A. Brown, 2015: An automated, multiparameter dryline identification algorithm. Wea. Forecasting, 30, 1781-1794, https://doi.org/10.1175/WAF-D-15-0070.1.

Dee, D. P., and Coauthors, 2011: The ERA-Interim reanalysis: Configuration and performance of the data assimilation system. Quart. J. Roy. Meteor. Soc., 137, 553-597, https://doi.org/ 10.1002/qj.828.

Duell, R. S., and M. S. Van Den Broeke, 2016: Climatology, synoptic conditions, and misanalyses of Mississippi River valley drylines. Mon. Wea. Rev., 144, 927-943, https://doi.org/ 10.1175/MWR-D-15-0108.1.

Garreaud, R., 2000: Cold air incursions over subtropical South America: Mean structure and dynamics. Mon. Wea. Rev., 128, 2544-2559, https://doi.org/10.1175/1520-0493(2000)128<2544: CAIOSS $>2.0 . \mathrm{CO} ; 2$.

Golden, J. H., 1980: Forecasting and research on severe storms in China: A summary of two seminars. Bull. Amer. Meteor. Soc., 61, 7-21, https://doi.org/10.1175/1520-0477(1980)061<0007: $\mathrm{SNFARO}>2.0 . \mathrm{CO} ; 2$.

Hamilton, R. A., J. W. Archbold, and C. K. M. Douglas, 1945: Meteorology of Nigeria and adjacent territory. Quart. J. Roy. Meteor. Soc., 71, 231-264, https://doi.org/10.1002/qj.49707130905.

Hoch, J., and P. Markowski, 2005: A climatology of springtime dryline position in the U.S. Great Plains region. J. Climate, $\mathbf{1 8}$ 2132-2137, https://doi.org/10.1175/JCLI3392.1.

Lichtenstein, E. R., and M. L. Schwarzkopf, 1966: Squall-lines in Argentina. Weather, 21, 181-186, https://doi.org/10.1002/ j.1477-8696.1966.tb02843.x. 
Lin, Y.-L., 2007: Mesoscale Dynamics. Cambridge University Press, 630 pp., https://doi.org/10.1017/CBO9780511619649.

Marengo, J. A., W. R. Soares, C. Saulo, and M. Nicolini, 2004: Climatology of the low-level jet east of the Andes as derived from the NCEP-NCAR reanalyses: Characteristics and temporal variability. J. Climate, 17, 2261-2280, https://doi.org/ 10.1175/1520-0442(2004)017<2261:COTLJE >2.0.CO;2.

Markowski, P., and Y. Richardson, 2010: Mesoscale Meteorology in Midlatitudes. John Wiley and Sons, 430 pp., https://doi.org/ 10.1002/9780470682104.

Neiman, P. J., and R. M. Wakimoto, 1999: The interaction of a Pacific cold front with shallow air masses east of the Rocky Mountains. Mon. Wea. Rev., 127, 2102-2127, https://doi.org/ 10.1175/1520-0493(1999)127<2102:TIOAPC >2.0.CO;2.

Owen, J., 1966: A study of thunderstorm formation along dry lines. J. Appl. Meteor., 5, 58-63, https://doi.org/10.1175/15200450(1966)005<0058:ASOTFA $>2.0 . \mathrm{CO} ; 2$.

Qin, R., and M. Chen, 2017: Impact of a front-dryline merger on convection initiation near a mountain ridge in Beijing. Mon. Wea. Rev., 145, 2611-2633, https://doi.org/10.1175/MWR-D16-0369.1.

Ribeiro, B. Z., and L. F. Bosart, 2018: Elevated mixed layers and associated severe thunderstorm environments in South and North America. Mon. Wea. Rev., 146, 3-28, https://doi.org/ 10.1175/MWR-D-17-0121.1.

_- M. E. Seluchi, and S. C. Chou, 2016: Synoptic climatology of warm fronts in southeastern South America. Int. J. Climatol., 36, 644-655, https://doi.org/10.1002/joc.4373.

Salio, P., M. Nicolini, and A. C. Saulo, 2002: Chaco low-level jet events characterization during the austral summer season. J. Geophys. Res., 107, 4816, https://doi.org/10.1029/2001JD001315.

Sandu, I., A. Beljaars, P. Bechtold, T. Mauritsen, and G. Balsamo, 2013: Why is it so difficult to represent stably stratified conditions in numerical weather prediction (NWP) models? J. Adv. Model. Earth Syst., 5, 117-133, https://doi.org/10.1002/jame.20013.

Saulo, C., L. Ferreira, J. Nogués-Paegle, M. Seluchi, and J. Ruiz, 2010: Land-atmosphere interactions during a northwestern
Argentina low event. Mon. Wea. Rev., 138, 2481-2498, https:// doi.org/10.1175/2010MWR3227.1.

Schaefer, J. T., 1974: The life cycle of the dryline. J. Appl. Meteor., 13, 444-449, https://doi.org/10.1175/1520-0450(1974) $013<0444$ :TLCOTD $>2.0$. CO 2 .

_ 1986: The dryline. Mesoscale Meteorology and Forecasting, P. S. Ray, Ed., Amer. Meteor. Soc., 549-572.

Schultz, D. M., C. C. Weiss, and P. M. Hoffman, 2007: The synoptic regulation of dryline intensity. Mon. Wea. Rev., 135, 16991709, https://doi.org/10.1175/MWR3376.1.

Seluchi, M. E., A. C. Saulo, M. Nicolini, and P. Satyamurty, 2003: The northwestern Argentinean low: A study of two typical events. Mon. Wea. Rev., 131, 2361-2378, https://doi.org/ 10.1175/1520-0493(2003)131<2361:TNALAS >2.0.CO;2.

- R. Garreaud, F. A. Norte, and A. C. Saulo, 2006: Influence of the subtropical Andes on baroclinic disturbances: A cold front case study. Mon. Wea. Rev., 134, 3317-3335, https://doi.org/ 10.1175/MWR3247.1.

Sun, W.-Y., and Y. Ogura, 1979: Boundary-layer forcing as a possible trigger to a squall-line formation. J. Atmos. Sci., 36, 235-254, https://doi.org/10.1175/1520-0469(1979)036<0235: BLFAAP $>2.0 . \mathrm{CO} ; 2$.

Taylor, N. M., and Coauthors, 2011: The Understanding Severe Thunderstorms and Alberta Boundary Layers Experiment (UNSTABLE) 2008. Bull. Amer. Meteor. Soc., 92, 739-763, https://doi.org/10.1175/2011BAMS2994.1.

Weston, K. J., 1972: The dry-line of northern India and its role in cumulonimbus convection. Quart. J. Roy. Meteor. Soc., 98, 519-531, https://doi.org/10.1002/qj.49709841704.

Wilson, J. W., and R. D. Roberts, 2006: Summary of convective storm initiation and evolution during IHOP: Observational and modeling perspective. Mon. Wea. Rev., 134, 23-47, https:// doi.org/10.1175/MWR3069.1.

Ziegler, C. L., W. J. Martin, R. A. Pielke, and R. L. Walko, 1995: A modeling study of the dryline. J. Atmos. Sci., 52, 263-285, https://doi.org/10.1175/1520-0469(1995)052<0263: AMSOTD $>2.0 . \mathrm{CO} ; 2$. 